\title{
PERÍCIA CONTÁBIL: ANÁLISE DAS CONDIC̣ÕES DE ENSINO EM CURSOS DE CIÊNCIAS CONTÁBEIS DA REGIÃO METROPOLITANA DE SÃO PAULO'
}

\author{
Ivam Ricardo Peleias* \\ Martinho Maurício Gomes de Ornelas** \\ Marcelo Rabelo Henrique*** \\ Elionor Farah Jreige Weffort ${ }^{* * * *}$
}

RESUMO: A Perícia Contábil é uma opção de atuação profissional para os futuros contadores. A legislação sobre o ensino superior da Contabilidade no Brasil, promulgada a partir dos anos 1990, voltou a determinar a oferta de Perícia Contábil, o que permitiu que os futuros bacharéis em Ciências Contábeis que optarem por atuar como peritos contábeis sejam preparados para atender as demandas profissionais que lhes forem impostas. O objetivo geral do trabalho é identificar e analisar as condições de ensino da disciplina Perícia Contábil em cursos de Ciências Contábeis na Região Metropolitana de São Paulo. É uma pesquisa descritiva e de caráter qualitativo, que requereu um levantamento de campo de natureza documental. Foram obtidos e analisados os planos de ensino da disciplina Perícia Contábil em dois grupos de cursos: o primeiro com sete classificados pelo Enade de 2006; o segundo com dez, escolhidos por acessibilidade. A análise documental revelou a evolução histórica no ensino de Perícia Contábil na legislação sobre o ensino da Contabilidade no Brasil. Constatou-se que a oferta de conteúdos para disciplinas correlatas na América do Norte é estimulada pela sociedade e pelo mercado de trabalho, ao contrário do Brasil, cujo comando é a lei. A análise documental dos planos de ensino, realizada por meio da análise de conteúdo, apontou que os cursos classificados pelo Enade possuem melhores condições de ensino, revelando maiores preocupações e cuidados com: estratificação dos grupos de conteúdos oferecidos, completude dos planos de ensino, variação nas estratégias de ensino, ênfase em determinados grupos de conteúdos e variedade nos critérios de avaliação.

Palavras-chave: Perícia Contábil. Ensino Superior de Contabilidade. Brasil.

\footnotetext{
* Doutor em Ciências Contábeis pela Universidade de São Paulo (USP) e Professor e Pesquisador do Centro Universitário da Fundação Escola de Comércio Álvares Penteado (FECAP) e da Pontifícia Universidade Católica de São Paulo (PUC-SP). E-mail: ivamrp@fecap.br

** Doutor em Ciências Contábeis pela Universidade de São Paulo (USP). E-mail: m.ornelas@contadoresforenses.net.br

** Mestre em Ciências Contábeis pelo Centro Universitário da Fundação Escola de Comércio Álvares Penteado (FECAP) e Professor da Universidade Camilo Castelo Branco (UNICASTELO). E-mail: marcelo@apligraf.com.br

**** Doutora em Ciências Contábeis pela Universidade de São Paulo (USP) e Professora e Pesquisadora do Centro Universitário da Fundação Escola de Comércio Álvares Penteado (FECAP). E-mail: eweffort@gmail.com
} 


\section{FORENSIC ACCOUNTING: ANALYSIS OF TEACHING CONDITIONS} IN ACCOUNTANCY BACHELOR COURSES IN SAO PAULO METROPOLITAN AREA - BRAZIL

ABSTRACT: Forensic Accounting is an option of professional career for future accountants. The Brazilian legislation concerning the teaching of Accountancy in Brazil, promulgated in the 1990s, is considering Forensic Accounting again, so as to allow future accountants who choose to work as Forensic Accountants to prepare themselves for their future demands. In this context, the aim of this work is to identify and analyze the teaching conditions of Forensic Accounting in Accountancy Bachelor courses in Sao Paulo city. This is a descriptive research, with qualitative features, and it was necessary a field research with documental background. The course syllabus for the teaching of Forensic Accounting were obtained and analyzed in two course groups: in the first one, there were seven courses classified in Enade 2006; and in the second, ten, chosen due to availability. The documental analysis revealed the historical evolution in the teaching of Forensic Accounting in the Brazilian legislation, concerning the teaching of Accountancy in this country. It was verified that the content offer for similar subjects in North America is stimulated by the society and the job market. In contrast, in Brazil this is made through the law. The documental analysis of the course syllabus was carried out through the content analysis. In such a process, it was verified that the courses classified in Enade have the best teaching conditions, and this shows more concern and care about: group stratification of the offered content, more detailed course syllabus, variety in the strategies of teaching, focus on certain content groups and variety of criteria of evaluation.

Keywords: Forensic Accounting. Accountancy Bachelor Courses. Brazil.

\section{INTRODUC̣ÃO}

A Perícia Contábil é um meio de prova à disposição dos que dela necessitam, nas esferas judicial e extrajudicial (nesta incluído o juízo arbitral), para a solução de controvérsias de natureza técnica e científica sobre questões relativas ao patrimônio de pessoas e sociedades. É um serviço prestado pelo contador, na função de perito contábil, para auxiliar os tomadores de decisões: os juízes federais e estaduais e os membros dos tribunais arbitrais. A realização do exame pericial contábil requer elementos de prova obtidos no sistema contábil das entidades. Quanto mais organizada e atualizada a contabilidade, melhores serão os resultados do exame pericial.

A Perícia Contábil deve conter certos requisitos que constituem o conjunto de procedimentos técnicos e científicos destinados a levar à instância decisória elementos de prova aos que dela necessitam. Esses 
requisitos e procedimentos podem se materializar em dois relatórios: o laudo e o parecer pericial contábil, os quais devem observar as normas profissionais e a legislação específica no que for pertinente. O Perito Contábil deve ser tecnicamente qualificado, conhecer os aspectos legais, as normas contábeis de Perícia Contábil e dominar a matéria a ser analisada ou investigada. Esse cenário remete à discussão sobre a formação dos bacharéis em Ciências Contábeis.

A educação para futuros contadores deve produzir profissionais com expertise contábil e que dominem certas habilidades, entre as quais as de comunicação e conhecimentos gerais (MARION, 2001, p. 14). Essa assertiva conduz à reflexão sobre a importância e a utilidade da Perícia Contábil e das condições para o seu exercício profissional. Os futuros contadores precisam adquirir e desenvolver competências e habilidades técnicas contábeis, de comunicação e de conhecimentos gerais. A frequência ao curso de graduação é parte da trajetória necessária a tal qualificação.

No Brasil, o marco para a definição e a efetivação das condições de ensino de Perícia Contábil em cursos de Contabilidade vem sendo o comando legal, e não o mercado de trabalho, de forma distinta do que ocorre na América do Norte, situação percebida e analisada na revisão da literatura (STIMPSON, 2007; BROOKS; LABELLE, 2006; ROSEN, 2006; REZAEE; LANDER; GAVIN, 1992) A Resolução CNE/CES n. 10/2004 descreve, no artigo $4^{\circ}$, as condições mínimas que o curso de Ciências Contábeis deve fornecer para a formação do futuro contador no Brasil: visão sistêmica, interdisciplinaridade da atividade contábil, aplicação adequada da legislação inerente às funções contábeis, entre outras.

Essa Resolução propugna que o curso deve formar um profissional apto a interagir com o contexto atual, adequando-se às necessidades da sociedade globalizada. Assim, é de esperar que os programas dos cursos de Ciências Contábeis sejam bem-delineados, voltados à prática contábil contemporânea, com referencial bibliográfico atualizado. Isso requer professores qualificados nas disciplinas e nos conteúdos, como, por exemplo, Perícia Contábil, para se obter bom desempenho nas atividades do ensino.

A frequência dos discentes à disciplina Perícia Contábil requer conhecimentos acadêmicos, habilidades e competências obtidas durante o curso de graduação, os quais poderiam ser mais bem-estudados quando 
atrelados à vivência prática do professor, exemplificados e ilustrados no decorrer da disciplina. Essa situação pode contribuir para a melhor aprendizagem dos alunos para que, no futuro, possam vir a exercer a função de Perito Contábil.

Algumas razões para a oferta de Perícia Contábil ao final do curso são: o discente foi exposto a vários conteúdos e disciplinas ao longo do currículo, o que permite estabelecer as inter-relações para a compreensão do que seja Perícia Contábil; muitos já estão atuando profissionalmente, situação que também potencializa o aprendizado da disciplina.

Esse cenário permite formular e buscar resposta à seguinte questão de pesquisa: Quais são as condições de ensino de Perícia Contábil expressas nos planos de ensino da disciplina em dois grupos de cursos de Ciências Contábeis na Região Metropolitana de São Paulo?

O objetivo geral foi identificar e analisar as condições de ensino da disciplina Perícia Contábil em cursos de Ciências Contábeis na região informada. Os objetivos específicos foram: identificar os conteúdos ministrados, a carga horária, a bibliografia básica e complementar ofertados nos planos de ensino da disciplina; pesquisar a qualificação acadêmica dos docentes que ministram a disciplina Perícia Contábil.

Várias razões justificaram a realização da presente pesquisa. Do ponto de vista acadêmico, tem-se:

- a possibilidade de contribuir para a continuidade e o aprimoramento de pesquisas já realizadas sobre as condições de ensino de conteúdos e/ou disciplinas em cursos de graduação em Ciências Contábeis (HOFER; PELEIAS; WEFFORT, 2005; PELEIAS et al., 2008);

- a escassez, constatada até a data de conclusão deste trabalho, de pesquisas tendo como objeto de estudo os planos de ensino e/ou programas de curso em cursos de Ciências Contábeis e nas áreas de negócios, no exterior e no Brasil (MARCIS et al., 2005; PELEIAS et al., 2008);

- explorar outros aspectos que não foram identificados ou não explorados por trabalhos de mesma natureza anteriormente realizados;

- contribuir para o desenvolvimento de uma metodologia e de um instrumento de pesquisa qualitativa que permitam a outros interessados identificar e analisar as condições de ensino de conteúdos e/ou disciplinas em cursos de graduação em Ciências Contábeis;

- oferecer aos professores, coordenadores de cursos, órgãos de classe e demais interessados no ensino superior da Contabilidade subsí- 
dios extraídos da observação sistemática da realidade que os ajudem a melhorar a formação dos atuais e futuros bacharéis em Ciências Contábeis e a aprimorar e ampliar as condições de ensino.

Do ponto de vista da atuação profissional, tem-se:

- o exercício da função pericial é uma opção profissional para os bacharéis em Ciências Contábeis;

- a Perícia Contábil requer conhecimento técnico contábil e domínio de outras áreas e conteúdos, tais como Economia, Administração, Finanças, Sistemas de Informação e Legislação, entre outras;

- é de importância e utilidade social na solução de questões controversas.

\section{PLATAFORMA TEÓRICA}

\subsection{Evolução histórica do ensino de perícia contábil no Brasil: legislação, livros e normas}

O estudo da legislação promulgada no Brasil sobre o ensino comercial e de contabilidade revelou a primeira menção aos termos "Perito Judicial", "Perito Contador", "Perícia Contábil" e suas outras formas. Adicionalmente, revelou a evolução histórica da regulamentação do ensino e das condições de oferta.

A primeira menção a "Perito Judicial" está no Decreto n. $1.339 / 1905$, que mencionou, no parágrafo $1^{\circ}$ do art. $1^{\circ}$, a oferta de um curso de Perito Judicial. O Decreto n. 17.329/1926, que aprovou o regulamento para os estabelecimentos de ensino téchnico commercial reconhecidos officialmente ${ }^{2}$ pelo governo federal, foi o marco das diretrizes de ensino de Perícia Contábil. Constou, no artigo $3^{\circ}$, parágrafo único, que essses estabelecimentos poderiam manter cursos de especialização destinados a certas profissões, entre elas a de Perito Contador.

O Decreto n. 20.158/1931 trouxe duas mudanças: regulamentou a profissão de Contador, reorganizou o Ensino Comercial em três níveis e classificou o curso de Perito Contador no nível técnico, de três anos. O artigo $6^{\circ}$ contém a grade curricular do curso. Destaca-se, no $3^{\circ}$ ano, a disciplina "Prática do Processo Civil e Comercial", com conteúdos voltados à atividade pericial. O Decreto-lei n. 1535/1939 alterou a denominação 
para curso de Contador, sem evidenciar a oferta de disciplinas ou de conteúdos sobre Perícia Contábil.

O Decreto-lei n. 7.988/1945 instituiu o curso superior em Ciências Contábeis e Atuariais, com quatro anos. Determinou a oferta, no último ano, da disciplina "Revisões e Perícia Contábil". A Lei n. 1.401/1951 desdobrou o curso em dois bacharelados: Ciências Contábeis e Ciências Atuariais, mantendo a disciplina "Revisões e Perícia Contábil".

A legislação até aqui analisada mencionou a oferta de conteúdos de Perícia Contábil, ainda que a disciplina tivesse nomes distintos ao longo do tempo. Houve novas mudanças nos anos 1960, porém, não se constatou, no Parecer CFE n. 397/62 e na Resolução CFE s/n,/1963, menção à "Perícia Contábil", com esta ou outras denominações.

A menção explícita à Perícia Contábil voltou após três décadas, na Resolução CFE n. 03/1992, que fixou os conteúdos mínimos e a duração do curso de Ciências Contábeis. As disciplinas foram distribuídas em três categorias de conhecimentos. Perícia Contábil foi classificada na categoria II - conhecimentos obrigatórios de formação profissional específica.

O Parecer CNE/CES n. 67/2003 revogou o CNE/CES n. 146/2002, ambos sobre as diretrizes curriculares de cursos de graduação. O item 3.2.4 do Parecer CNE/CES n. 146/2002 abordou as Ciências Contábeis, propondo três grupos de conteúdos curriculares, sem mencionar Perícia Contábil.

O Parecer CNE/CES n. 0289/2003 acolheu grande parte das contribuições às diretrizes curriculares do curso de Ciências Contábeis, inclusive as relativas à atividade pericial e de arbitragem. Nos grupos de conteúdos curriculares do parecer, o de número II - "conteúdos de formação profissional" acolheu a necessidade de domínio das atividades de perícias e arbitragens.

A Resolução n. 06/2004 instituiu as Diretrizes Curriculares Nacionais do curso de Ciências Contábeis e manteve o grupo II - "conteúdos de formação profissional", reafirmando a necessidade de domínio das atividades de perícias e arbitragens. Tal situação foi mantida pelo Parecer CNE/CES n. 269/2004 e pela Resolução CNE/CES n. 10/2004.

A pesquisa nas leis revelou três marcos temporais. O primeiro, entre 1905 e 1945, tratou da Perícia Contábil no ensino comercial e técnico. O segundo, entre 1945 e 1992, revelou a Perícia Contábil como disciplina de curso superior, no primeiro momento oferecida juntamente com 
o termo "Revisões", seguida de um período sem menção nos comandos legais. O terceiro, a partir de 1992, trouxe de volta a menção ao termo "Perícia Contábil", acompanhado da obrigatoriedade da oferta de seus conteúdos. Os três marcos temporais estão apresentados no Quadro 1.

\section{QUADRO 1 \\ CRONOLOGIA DA LEGISLAÇÃO SOBRE O ENSINO DE CONTABILIDADE FONTE: OS AUTORES, COM BASE NA LEGISLAÇ̃̃O ANALISADA}

\begin{tabular}{|c|c|c|c|}
\hline ESTÁGIOS & ANO & TEXTO LEGAL & OCORRÊNCIA \\
\hline $1^{0}$ & 1931 & $\begin{array}{l}\text { Decreto n. } 20.158 \\
\text { Decreto Lei n. } 1.535\end{array}$ & $\begin{array}{l}\text { Declara instituições de utilidade publica a "Academia de Commercio do } \\
\text { Rio de Janeiro, reconhece os diplomas por ella conferidos, como de } \\
\text { caracter official; e dá outras providências". } \\
\text { Aprova o regulamento para os estabelecimentos de "ensino technico } \\
\text { commercial reconhecidos officialmente pelo Governo Federal". } \\
\text { Organiza o ensino comercial, regulamenta a profissão de contador } \\
\text { e dá outras providências. } \\
\text { Altera a denominação do curso de perito contador e dá outras providências. }\end{array}$ \\
\hline $2^{0}$ & $\begin{array}{l}1951 \\
1962 \\
1963\end{array}$ & \begin{tabular}{|c|} 
Decreto Lei $n .7 .988$ \\
Lei $n .1 .401$ \\
Parecer $n .397$ \\
Resolução CFE s.n., de 08/2/1963
\end{tabular} & $\begin{array}{c}\text { Dispõe sobre o ensino superior de ciências econômicas e de } \\
\text { ciências contábeis e autarias. } \\
\text { Inclui, no curso de ciências contábeis, a cadeira de história econômica geral e } \\
\text { do Brasil, e desdobra o curso de ciências contábeis e atuariais. } \\
\text { Divide os cursos de Ciências Contábeis nos ciclos de formação básica } \\
\text { e formaçãa profissional. } \\
\text { Fixa os mínimos de conteúdo e duração do curso de Ciências Contábeis } \\
\text { e ratifica o Parecer CFE. } 397 / 1962 .\end{array}$ \\
\hline $3^{0}$ & $\begin{array}{l}1992 \\
2002 \\
2003\end{array}$ & $\begin{array}{l}\text { Resolução CFE n. } 03 \\
\text { Parecer CES/CNE n. } 0146 \\
\text { Parecer CNE/CES n. } 67 \\
\text { Parecer CNE/CES n. } 289\end{array}$ & $\begin{array}{l}\text { Institui o currículo pleno, fixa a duração mínima de quatro anos para os cur- } \\
\text { sos diurnos e cinco anos para os cursos noturnos. } \\
\text { Define às diretrizes nacionais para os curso de Ciências Contábeis. } \\
\text { Referencial para as diretrizes curriculares nacionais (DCN) } \\
\text { dos cursos de graduação. } \\
\text { Aprova as diretrizes curriculares dos cursos de graduação em Ciências } \\
\text { Contábeis - bacharelado, a serem observadas pelas instituições de Ensino } \\
\text { Superior em sua organização curricular. } \\
\text { Oficializa o Parecer CNE/CES n. 289/2003. } \\
\text { Remove do texto da Resolução CNE/CES n.6/2004, a pedido do Instituto } \\
\text { Brasileiro de Atuária (IBA), o trecho que menciona a necessidade de inserção } \\
\text { da profissão contábil nos domínios da atividade atuarial. } \\
\text { A pedido do IBA, cancela e substitui a Resolução CNE/CES n. 6/2004. }\end{array}$ \\
\hline
\end{tabular}

No intervalo de tempo analisado, foi possível identificar e tabular a frequência de edição de livros sobre Perícia Contábil. Usou-se, ao delimitar os intervalos de tempo para a tabulação dos livros, denominados de pré-03/92 e pós-03/92, a Resolução CFE n. 03/92, que tornou obrigatória a oferta de conteúdos de Perícia Contábil. Foram consultados os catálogos das bibliotecas de três instituições de ensino superior integrantes da amostra objeto da pesquisa (FECAP, Mackenzie e PUC-SP), cujos cursos de Ciências Contábeis são oferecidos há mais tempo. Constatou-se a publicação de cinco livros no período pré-03/92 e 11 obras no período 
pós-03/92, as últimas com maior número de edições e reimpressões. $\mathrm{O}$ resultado está no Quadro 2.

\section{QUADRO 2}

LIVROS SOBRE PERÍCIA CONTÁBIL PUBLICADOS NO PERÍODO DE 1928 A 2007

\begin{tabular}{|c|c|c|c|c|c|}
\hline PERÍODO & AUTOR & LIVRO & EDIC̣ÃO & EDITORA & ANO \\
\hline \multirow{9}{*}{$\begin{array}{c}1928 \\
\text { a } \\
1991\end{array}$} & MARTINS, W. C. & Contabilidade empresarial, auditoria e perícia & $3^{\mathrm{a}}$ & Hemus & 1970 \\
\hline & MARTINS, W. C. & $\begin{array}{l}\text { Manual técnico de contabilidade: } 3^{\circ} \text { volume: } \\
\text { Elementos de revisão e perícia contábil }\end{array}$ & $1^{\mathrm{a}}$ & Atlas & 1968 \\
\hline & SANTOS, J. L. & Perícia em contabilidade commercial & $2^{\mathrm{a}}$ & Jornal do Brasil & 1928 \\
\hline & D'ÁURIA, F. & Perícia contábil: parte aplicada & São Paulo & Cia. Editora Nacional & 1955 \\
\hline & GONÇALVES, A.F. & $\begin{array}{l}\text { Auditoria fiscal de empresas: patrimônio e reditos, imposto } \\
\text { de renda (1965-1971), roteiro de perícia contábil-fiscal/1971 }\end{array}$ & São Paulo & Não informada & 1971 \\
\hline & ALBERTO, V. L. P. & $\begin{array}{l}\text { Perícia contábil } \\
\end{array}$ & $\begin{array}{l}1^{\mathrm{a}} \\
2^{\mathrm{a}} \\
3^{\mathrm{a}} \\
4^{\mathrm{a}} \\
\end{array}$ & Atlas & $\begin{array}{l}1996 \\
2000 \\
2002 \\
2007 \\
\end{array}$ \\
\hline & DALLA ZANNA, $\mathrm{R}$. & Prática de perícia contábil & & IOB Thomson & 2005 \\
\hline & $\begin{array}{l}\text { HOOG, W. A. Z.; } \\
\text { PETRENCO, S. A. }\end{array}$ & $\begin{array}{l}\text { Prova pericial contábil: } \\
\text { aspectos práticos \& fundamentais }\end{array}$ & $\begin{array}{l}1^{\mathrm{a}} \\
2^{\mathrm{a}} \\
4^{\mathrm{a}} \\
5^{\mathrm{a}} \\
6^{\mathrm{a}}\end{array}$ & Juruá & $\begin{array}{l}2001 \\
2002 \\
2006 \\
2007 \\
2008 \\
\end{array}$ \\
\hline & MAGALHÃES, A. D. F. & $\begin{array}{c}\text { Perícia contábil: uma abordagem teórica, ética, legal, } \\
\text { processual e operacional }\end{array}$ & $\begin{array}{l}1^{\mathrm{a}} \\
2^{\mathrm{a}} \\
3^{\mathrm{a}} \\
4^{\mathrm{a}} \\
5^{\mathrm{a}} \\
6^{\mathrm{a}}\end{array}$ & Atlas & $\begin{array}{l}1995 \\
1998 \\
2001 \\
2004 \\
2006 \\
2008\end{array}$ \\
\hline \multirow{7}{*}{$\begin{array}{c}1992 \\
a \\
2008\end{array}$} & MOURA, R. & Perícia contábil: judicial e extrajudicial & $2^{\mathrm{a}}$ & Freitas Bastos & 2007 \\
\hline & NEVES, A. G. & Curso básico de perícia contábil & $2^{\mathrm{a}}$ & $\mathrm{LTr}$ & 2004 \\
\hline & $\begin{array}{l}\text { OLIVEIRA NETO, C. E.; } \\
\text { MERCANDALE, I. }\end{array}$ & $\begin{array}{l}\text { Roteiro prático de perícia contábil judicial: legislação - } \\
\text { modelos - índices oficiais }\end{array}$ & & Oliveira Mendes & 1998 \\
\hline & ORNELAS, M. M. G. & $\begin{array}{l}\text { Perícia contábil } \\
\end{array}$ & $\begin{array}{l}1^{\mathrm{a}} \\
2^{\mathrm{a}} \\
3^{\mathrm{a}} \\
4^{\mathrm{a}}\end{array}$ & Atlas & $\begin{array}{l}1994 \\
1995 \\
2000 \\
2007\end{array}$ \\
\hline & SÁ, A. L. & Perícia contábil & $\begin{array}{l}1^{\mathrm{a}} \\
3^{\mathrm{a}} \\
5^{\mathrm{a}} \\
7^{\mathrm{a}}\end{array}$ & Atlas & $\begin{array}{l}1994 \\
1997 \\
2002 \\
2005\end{array}$ \\
\hline & $\begin{array}{l}\text { SCHMIDT, P.; } \\
\text { GOMES, J. M. M. }\end{array}$ & Fundamentos de perícia contábil & & Atlas & 2006 \\
\hline & SILVA, M. A. & Fundamentos de perícia contábil: teoria e prática & & UMESP & 2005 \\
\hline
\end{tabular}

Constatou-se também o início da promulgação de Normas Brasileiras de Contabilidade sobre Perícia Contábil pelo Conselho Federal de Contabilidade-CFC, a partir de 1992. Essas normas estão divididas nas categorias "Profissional" e "Técnica", identificadas e diferenciadas pelas letras "P" e "T". Foram originalmente promulgadas duas normas em 1992, posteriormente desdobradas em quinze, três das quais, revogadas. Em dezembro de 2009, foram promulgadas duas normas, uma profissio- 
nal (BRASIL, 2009a) e outra técnica (BRASIL, 2009b), fundindo as doze até então vigentes. Essa fusão significa o retorno à situação de 1992.

Nota-se o crescimento na publicação de livros e a maior preocupação com a edição de normas aplicáveis à atividade pericial, a partir da Resolução CFE n. 03/92. Infere-se que tais ocorrências trouxeram benefícios ao ensino de Perícia Contábil em cursos de Ciências Contábeis.

\subsection{Pesquisas sobre o ensino de Perícia Contábil no Brasil}

Matos (2004) pesquisou, junto aos docentes de Ciências Contábeis de Salvador, quais tópicos deveriam compor o contéudo programático da disciplina Perícia Contábil e as obras indicadas por tópico. Apontou 28 tópicos a serem abordados, por ordem de importância, a maioria presente nos planos de ensino da disciplina nos cursos de Ciências Contábeis de Salvador e nos sumários das três obras mais recomendadas pelos docentes pesquisados.

O estudo de Buosi (1999) considerou a obrigatoriedade da inclusão de Perícia Contábil nos Cursos de Ciências Contábeis a partir da Resolução CFE n. 03/92 e teve dois objetivos: a) conhecer a realidade do ensino da disciplina no estado de São Paulo e b) conhecer o perfil dos Peritos Contábeis à época de sua realização. Obteve respostas em 23 das 63 IES que consultou, com 22 coordenadores de curso, 16 chefes de departamento e 6 docentes da disciplina.

Alguns achados foram: a disciplina não era oferecida antes da Resolução CFE n. 03/92 na maioria das IES pesquisadas e os professores não possuíam mestrado em Ciências Contábeis; a disciplina estava em seus primórdios no Brasil, por ser atividade pouco divulgada; havia poucos peritos e professores que cursaram a disciplina na graduação; os coordenadores informaram haver poucos docentes para lecioná-la; a maioria dos entrevistados considerou importante a obrigatoriedade da disciplina na graduação, para a boa formação do futuro contador.

Neves Jr. e Brito (2007) estudaram as percepções de onze docentes de Perícia Contábil em IES do Distrito Federal sobre o ensino da disciplina, buscando construir uma proposta de ensino que capacitasse os discentes. Constataram que: a disciplina é oferecida nas 11 IES; todos consideraram importante ter domínio empírico e acadêmico para lecionála; $81,9 \%$ concordaram que o projeto pedagógico do curso contempla o 
perfil e as competências para a formação do Perito; $72,8 \%$ discordaram da suficiência da carga horária semestral para formar o Perito; todos concordaram sobre a necessidade de práticas periciais na disciplina, a realização de pesquisas e palestras; as técnicas pedagógicas relatadas pelos docentes foram: $45 \%$ aula tradicional, $5 \%$ painel simples, $15 \%$ painel integrado, $25 \%$ estudo de caso e 10\% simulação. Concluíram pela necessidade da educação continuada para a melhor qualificação dos futuros Peritos e pela otimização das técnicas de ensino de Perícia Contábil.

Pereira (2006) realizou pesquisa com juízes de Direito dos estados de São Paulo e Minas Gerais, para obter opiniões sobre temas a serem incluídos nos conteúdos de Perícia Contábil. Após, submeteu os temas indicados a professores da disciplina no estado de São Paulo, para obter opiniões e sugestões de metodologias de ensino. A questão investigada foi a de como promover o processo de ensino e aprendizagem de Perícia Contábil no curso de Ciências Contábeis, para agilizar o exercício da função pericial pelos então egressos.

Constatou (2006, p. 167) que 100\% das IES pesquisadas ofereciam a disciplina como obrigatória, no último ano. Ofereceu uma proposta de 28 conteúdos programáticos, com base nas sugestões dos juízes, ratificadas pelos docentes, além da metodologia de ensino indicada pelos respondentes. A pesquisa revelou a confusão da estratégia (ou metodologia) de ensino do "método do caso" com a técnica de pesquisa do "estudo de caso" (indicada para oito conteúdos sugeridos), além do que os 28 conteúdos programáticos sugeridos requereriam mais do que um semestre para a disciplina Perícia Contábil.

A confusão entre o método do caso aplicado ao ensino e o método do estudo de caso como técnica de estudos qualitativos foi apontada por César (2005). Em seu trabalho, a autora se propôs apresentar as conceituações de ambos, aplicações em atividades de ensino e pesquisa, bem como a necessidade de que o uso específico de um ou outro requer rigor metodológico.

\subsection{0 cenário internacional}

No cenário internacional, há os termos Pericia Contable, na Espanha, Expertise Comptable, na França, Forensic Accounting, nos Estados Unidos, e Forensic and Investigative Accounting, no Canadá. Foram localizados 
e analisados trabalhos sobre as condições de oferta de disciplina correlata na América do Norte. Os trabalhos localizados em língua espanhola e francesa são de natureza técnica e não foram encontrados artigos sobre o ensino de Perícia Contábil.

Destacou-se o escopo de atuação do Forensic Accountant, nos Estados Unidos, e do Forensic and Investigative Accountant, no Canadá, a preocupação em distinguir a atuação desses e dos auditores, e o fato de que, na América do Norte, os profissionais são indicados pelas partes que litigam na justiça (STIMPSON, 2007; BROOKS; LABELLE, 2006; ROSEN, 2006; REZAEE; LANDER; GAVIN, 1992), diferentemente do Brasil, onde o Juiz Público ou o Presidente do Tribunal Arbitral nomeiam Perito de sua confiança. Os trabalhos analisados apontaram maior escopo de atuação daqueles profissionais, em comparação com o relato da literatura brasileira para o Perito Contábil. Mereceu análise a demanda para o ensino de Forensic (and Investigative) Accounting a partir da realidade e do mercado de trabalho, e o consequente impacto nos cursos de Contabilidade.

O trabalho de Rezaee, Lander e Gavin (1992) revela que a discussão sobre o ensino de Forensic Accounting, nos Estados Unidos, é anterior aos escândalos contábeis do início do século XXI. Os autores consideraram Forensic Accounting uma especialização em evolução, o que os motivou a buscar por que e como deveria se integrar ao currículo dos cursos de Contabilidade. Apresentaram o escopo e a natureza de Forensic Accounting, os tópicos a serem oferecidos no currículo, em disciplinas separadas ou em módulos integrados aos cursos e disciplinas de auditoria, juntamente com técnicas e os materiais de referência para o ensino. Os autores (1992) propugnaram a melhoria do ensino de Contabilidade via a inclusão da disciplina nos curricula dos cursos, por estar se tornando uma atraente opção profissional para os futuros Contadores.

O trabalho de Rosen (2006) é parte de um fórum de discussões sobre Forensic Accounting no cenário pós-escândalo Enron e analisou as condições de oferta da disciplina nos cursos de Contabilidade no Canadá, apresentando outros elementos relevantes sobre a atuação profissional do Contador que optar por essa especialidade. Apontou que os cursos de Contabilidade no Canadá preparam os futuros Contadores para os exames de certificação profissional, em especial em auditoria, negligenciando o ensino de Forensic Accounting. Para ele (2006), a ênfase no tecnicismo gera 
profissionais obsoletos em pouco tempo, colocando-os em desvantagem na atuação conjunta com juízes e advogados. Esses, por serem, segundo o autor, melhor formados e treinados, rapidamente notariam os efeitos do tecnicismo sobre os futuros Contadores, comprometendo a credibilidade do trabalho apresentado.

Rosen (2006) ofereceu uma lista de atitudes e competências que o profissional deve ter para ser respeitado e reiterou que o Forensic Accountant não pode ser tecnicista, pois, ao longo de sua atuação, trabalhará com leigos em matéria contábil. Além disso, a maioria das demandas judiciais é específica, o que requer habilidade para a rápida compreensão da matéria discutida, visando ao delineamento do plano de trabalho.

Peterson (2003) defendeu a necessidade de maior ensino sobre fraudes em cursos e disciplinas de Contabilidade nos Estados Unidos. Relatou os esforços da Association of Certified Frand Examiners (ACFE) e do American Institute of Certified Public Accountants (AICPA) nesse sentido, em função das pressões sobre a profissão contábil geradas por escândalos contábeis, tais como Enron e WorldCom, de razões apontadas no US News \& World Report, que listou a carreira de Forensic Accountant como uma das oito mais seguras no país, e o fato de cerca $40 \%$ das principais firmas de contabilidade norte-americanas estarem expandindo a oferta de serviços de investigação de fraudes e apoio a processos judiciais.

Para a autora (2003, p. 263-264), "devido à magnitude dos problemas causados pelas fraudes e a frequência com a qual os auditores foram associados a tais casos, seria de se esperar que os curricula de cursos de Contabilidade incluissem mais tópicos sobre fraudes". Porém, não foi o que ela evidenciou em sua pesquisa, que revelou limitada oferta desses tópicos. Como razões para essa situação, apontou (2003, p. 264) "a dificuldade de entendimento sobre a extensão de uma fraude e suas consequências, além da falta de espaço nos currícula dos cursos de Contabilidade".

Ao final, Peterson (2003, p. 265) ofereceu uma proposta de curso sobre fraudes, com conteúdos e materiais a serem usados. Concluiu que a melhor formação dos futuros Contadores sobre fraudes os capacitaria a prestar melhores serviços às empresas e à sociedade como um todo.

Outro trabalho do fórum de discussões sobre Forensic Accounting é o de Brooks e Labelle (2006), que analisou e apontou evidências para 
melhorar o ensino da disciplina no Canadá. Os autores (2006) buscaram oferecer insights sobre os serviços prestados por esses profissionais, analisaram os conhecimentos, as habilidades e os atributos deles requeridos, juntamente com os desafios inerentes a programas de ensino e formação necessários à sua preparação. Também para esses autores, os futuros Contadores precisam conhecer melhor os negócios e como as fraudes ocorrem, o que os habilitaria a prestar melhor serviço.

Brooks e Labelle (2006) listaram os resultados de suas pesquisas sobre conteúdos e estratégias de ensino aplicáveis a Forensic and Investigative Accounting e ofereceram uma proposta detalhada de como preparar e oferecer a disciplina em cursos de Contabilidade. Ao final, destacaram que os estudantes e profissionais de Contabilidade precisam entender que o Forensic and Investigative Accountant pode atuar de forma preventiva, como investigador profissional que ajuda a resolver problemas de fraudes e outras disputas legais em potencial.

Ponemon (1998) estudou a interdisciplinaridade entre a Contabilidade e outras áreas de conhecimento, e apontou que a maior oferta de novos serviços por empresas de Contabilidade entre 1980 e 1990 requereu um novo modelo de atuação para essas entidades. Para ele (1998), a oferta de serviços contábeis não tradicionais, entre os quais Forensic Investigations, instou as empresas a contratarem especialistas de outras áreas, o que requereu maior interação conceitual e prática com os Contadores. Ponemon (1998) concluiu que essa situação afeta os curricula dos cursos de Contabilidade e os exames de certificação profissional, o que permite deduzir que os conteúdos de Forensic Accounting deveriam ser oferecidos ao longo dos cursos e cobrados nos exames.

\section{METODOLOGIA DE PESQUISA}

A pesquisa é descritiva, de campo e histórica, apoiada em técnicas de análise documental sobre a legislação e os planos de ensino obtidos, bibliográfica (MALHOTRA, 2006; COOPER; SCHINDLER, 2003; VERGARA, 2003; LUNA, 2002), e de análise de conteúdo (BARDIN, 2004). O planejamento e a revisão da literatura ocorreram durante o segundo semestre de 2007; a coleta dos dados, a análise e a apresentação dos resultados ocorreu durante 2008 . 
Foram obtidos os planos de ensino da disciplina Perícia Contábil, com esta ou outras denominações, junto aos professores de dois grupos de IES na Região Metropolitana de São Paulo: o primeiro com sete dos melhores cursos da região, segundo o Enade de 2006; o segundo com dez cursos escolhidos por acessibilidade. A amostra alcançou 21,8\% dos 78 cursos da região cadastrados no Inep - Instituto Nacional de Estudos e Pesquisas Educacionais, à época da pesquisa.

O grupo 1 reunia sete cursos com nota 4 (quatro): Faculdade São Luiz; Faculdade Sumaré; Universidade Paulista - Unip; Universidade Presbiteriana Mackenzie; Pontifícia Universidade Católica de São Paulo PUC-SP; Centro Universitário FECAP; Centro Universitário ÍtaloBrasileiro. O grupo 2 reunia cinco cursos com nota 3 (três): Universidade Camilo Castelo Branco; Universidade de Mogi das Cruzes; Universidade Nove de Julho - Uninove; Universidade Cruzeiro do Sul - Unicsul; Universidade Santo Amaro - Unisa. O mesmo grupo 2 continha cinco cursos com nota 2 (dois): Faculdade Famater; Faculdade Flamingo; Faculdade Sudoeste Paulistano; Faculdade Editora Nacional - Faenac; Centro Universitário Assunção - Unifai.

Pesquisou-se a formação acadêmica e a experiência profissional dos docentes como Perito Contábil e/ou Assistente Técnico. Parte dos planos de ensino e das informações sobre os docentes foi obtida via email e parte, pessoalmente, por meio de visita ao docente na IES. O objetivo inicial era pesquisar os dez cursos mais bem-classificados pelo Enade; porém, os docentes de três IES desse grupo alegaram acúmulo de trabalho como justificativa para não participar da investigação.

A decisão de obtenção e análise dos planos de ensino se baseou em pesquisas de mesma natureza (HOFER; PELEIAS; WEFFORT, 2005; MARCIS et al., 2005; PELEIAS et al., 2008) e na premissa de que, ao assumir a disciplina, o docente deve tomar várias decisões: decidir o que pretende que seus alunos aprendam; de que conteúdos tratará; que recursos usará (ABREU; MASETTO, 1990). Essas decisões instam o docente a planejar e a preparar o plano de ensino.

O plano de ensino direciona a ação dos docentes e é necessário ao processo de ensino e aprendizagem. Formaliza o compromisso do professor com o projeto pedagógico, evidencia o que será estudado no período letivo e de que forma (QUEIRÓZ; PALMA, 2006, p. 196). O plano de ensino é um meio de comunicação do professor com a comunidade uni- 
versitária (ABREU; MASETTTO, 1990; MARCIS et al., 2005). As proposições de Abreu e Masetto (1990) e de Queiróz e Palma (2006) foram ampliadas e aplicadas a esta pesquisa, com a seleção dos elementos constantes do Quadro 3, usado para criar o roteiro de análise dos planos de ensino obtidos.

\section{QUADRO 3 \\ ROTEIRO DE ANÁLISE DOS PLANOS DE ENSINO COLETADOS}

\begin{tabular}{|c|c|}
\hline ELEMENTOS & DESCRICCÃO \\
\hline EMENTA & Resumo expositivo dos conteúdos que serão tratados pela disciplina \\
\hline OBJETIVO & $\begin{array}{l}\text { Evidencia o alvo a ser alcançado, a finalidade específica da disciplina, que precisa estar inserida } \\
\text { no contexto do projeto pedagógico adotado pela IES. }\end{array}$ \\
\hline CONTEÚDO PROGRAMÁTICO & $\begin{array}{l}\text { Detalha os conteúdos, temas ou matérias a serem tratados na disciplina. } \\
\text { Caracteriza os compromissos da disciplina e do professor com o projeto pedagógico do curso. }\end{array}$ \\
\hline ESTRATÉGIAS DE ENSINO & $\begin{array}{l}\text { Meios usados pelo docente para transmitir os conteúdos aos alunos. Juntamente com os estímulos, } \\
\text { serevem para que o processo de ensino aprendizagem se materialize e alcance os objetivos estabelecidos. }\end{array}$ \\
\hline CRITÉRIOS DE AVALIAC̣ÃO & $\begin{array}{l}\text { Formas a serem usadas para avaliar o desempenho dos alunos ao longo da disciplina, } \\
\text { em função dos resultados por eles apresentados. }\end{array}$ \\
\hline CRONOGRAMA & $\begin{array}{l}\text { Representação cronológica para a execução das atividades previstas. } \\
\text { Define os prazos esperados para a realização das atividades. }\end{array}$ \\
\hline BIBLIOGRAFIA & $\begin{array}{l}\text { Deve abranger a literatura disponivel e atualizada, previamente avaliada e selecionada pelo docente, } \\
\text { composta por livros, artigos, revistas especializadas, dissertações e teses, e a indicação de outras } \\
\text { fontes de consulta, por exemplo, sites da internet. Pode ser dividida em básica e complementar. }\end{array}$ \\
\hline
\end{tabular}

A esses elementos adicionou-se o cabeçalho com a identificação da IES. A bibliografia foi dividida em básica e complementar. Usou-se a análise de conteúdo na avaliação dos planos de ensino, o que requereu as etapas de pré-análise e de categorização, as quais permitiram obter o plano de análise adotado (BARDIN, 2004).

A pré-análise é a fase de organização, um período de intuições. Busca operacionalizar e sistematizar as ideias iniciais para conduzir a um esquema preciso de realização das operações sucessivas, em um plano de análise. Foi preciso constituir um corpus, composto pelos documentos (os planos de ensino) a serem analisados, usando-se as regras de exaustividade, de representatividade e de homogeneidade.

Na sequência, definiu-se a categorização semântica a ser usada, com a criação de cinco grupos de assuntos, compostos pelos tópicos de conteúdos identificados nos planos de ensino. Os grupos foram criados após a análise do sumário das quatro obras mais indicadas pelos docentes nos planos de ensino: Ornelas, Sá, Magalhães e Alberto. A categorização orientou a análise dos conteúdos oferecidos e sua classificação por ordem de importância para cada grupo de IES. 
A análise dos planos de ensino buscou identificar a realidade das IES pesquisadas em relação ao ensino dos conteúdos de Perícia Contábil. $\mathrm{Na}$ observação dos elementos essenciais aos documentos, foram analisados os itens: conteúdos lecionados, bibliografias básica e complementar, carga horária, estratégias de ensino e critérios de avaliação. A Unip (grupo 1) e a Faculdade Famater (grupo 2) usam dois planos de ensino.

$\mathrm{Na}$ análise da bibliografia, buscou-se identificar a indicação de outras fontes, entre as quais artigos científicos, além dos livros-textos, por duas razões: todos os professores que participaram da pesquisa conhecem e convivem ou conviveram com o ambiente da pós-graduação stricto sensu, por serem ao menos mestrandos. Adicionalmente, buscou-se verificar se estava ocorrendo o circulo virtuoso de propagação dos conhecimentos citado por Ott (2008, p. 178), com a devolução das conquistas obtidas pela academia, em função da observação e do estudo sistemático da realidade que a cerca.

A apresentação dos dados obtidos nos planos de ensino foi feita por meio de quadros e tabelas, com a apresentação e a descrição dos itens analisados. A quantidade de planos de ensino estudada foi fator relevante na forma de apresentação dos dados, pois foram analisados 19 planos de ensino, elaborados por 17 IES.

\section{APRESENTAC̣ÃO E DISCUSSÃO DOS RESULTADOS}

Esta pesquisa buscou estudar dois grupos de IES para identificar e analisar as diferenças encontradas, diferentemente da forma adotada pelos trabalhos nacionais apresentados e comentados na revisão da literatura (BUOSI, 1999; MATOS, 2004; NEVES JR.; BRITO, 2007; PEREIRA, 2006), os quais analisaram amostras únicas. Os trabalhos internacionais analisados apontaram demandas da sociedade e do mercado de trabalho afetando o ensino da disciplina correlata na América do Norte, o que poderá ser investigado em outra oportunidade.

O primeiro resultado relatado é o momento de oferta da disciplina, no quarto ano para os dois grupos analisados. Na Unip e na Faculdade Famater há duas disciplinas, oferecidas no sétimo e oitavo semestres; nas demais, no oitavo, exceto pela Fecap (sétimo semestre). Essa constatação é aderente à legislação sobre o ensino de Contabilidade 
e se justifica pela necessidade de o discente já ter obtido conhecimentos contábeis ao longo do curso. Infere-se que estar nesse estágio do curso, juntamente com a atuação profissional, é uma situação que contribui para melhorar o aprendizado da disciplina.

Identificados e considerados os elementos que o plano de ensino deveria ter (ABREU; MASETTO, 1990; MARCIS et al., 2005; QUEIRÓZ; PALMA, 2006), o Quadro 4 condensa o resultado da análise dos itens que o compõe para as IES dos grupos 1 e 2.

\section{QUADRO 4}

\section{ANÁLISE DA ESTRUTURA DOS PLANOS DE ENSINO DE PERÍCIA CONTÁBIL}

\begin{tabular}{|c|c|c|c|c|c|c|c|c|c|c|c|c|c|c|c|c|c|c|}
\hline \multirow[b]{2}{*}{$\mathbf{N}^{\mathbf{0}}$} & \multirow[b]{2}{*}{ ITEM } & \multicolumn{7}{|c|}{ GRUPO 1} & \multicolumn{10}{|c|}{ GRUPO 2} \\
\hline & & 1 & 2 & 3 & 4 & 5 & 6 & 7 & 1 & 2 & 3 & 4 & 5 & 6 & 7 & 8 & 9 & 10 \\
\hline 1 & Cabeçalho e identificação da IES & $S$ & $S$ & $\mathrm{~N}$ & S & $S$ & $\mathrm{~S}$ & $S$ & $\mathrm{~S}$ & $\mathrm{~N}$ & $\mathrm{~S}$ & S & $S$ & $\mathrm{~N}$ & $\mathrm{~N}$ & $S$ & $\mathrm{~N}$ & $S$ \\
\hline 2 & Ementa & $S$ & S & S & $\mathrm{N}$ & $S$ & $\mathrm{~N}$ & S & $S$ & S & $S$ & $\mathrm{~N}$ & $S$ & S & $\mathrm{N}$ & $S$ & $\mathrm{~N}$ & $\mathrm{~N}$ \\
\hline 3 & Objetivos & $S$ & S & S & $\mathrm{N}$ & $S$ & $\mathrm{~N}$ & $S$ & $S$ & S & $S$ & $S$ & $S$ & $S$ & $\mathrm{~N}$ & $S$ & S & $S$ \\
\hline 4 & Conteúdo programático & $S$ & $\mathrm{~S}$ & $\mathrm{~S}$ & $\mathrm{~S}$ & S & $S$ & S & $\mathrm{S}$ & $\mathrm{N}$ & $\mathrm{S}$ & S & $\mathrm{S}$ & $\mathrm{S}$ & S & S & $S$ & $\mathrm{~S}$ \\
\hline 5 & Estratégias de ensino & $S$ & S & $S$ & $\mathrm{~N}$ & $S$ & $\mathrm{~N}$ & $S$ & $\mathrm{~N}$ & $\mathrm{~N}$ & $\mathrm{~N}$ & $\mathrm{~N}$ & $S$ & $S$ & $\mathrm{~N}$ & $S$ & $S$ & $S$ \\
\hline 6 & Avaliação de aprendizagem & $S$ & $\mathrm{~N}$ & $S$ & $\mathrm{~N}$ & $S$ & $\mathrm{~N}$ & $S$ & $\mathrm{~N}$ & $\mathrm{~N}$ & $\mathrm{~N}$ & $\mathrm{~N}$ & $S$ & $S$ & $\mathrm{~N}$ & $S$ & $S$ & $S$ \\
\hline 7 & Cronograma de atividades & $S$ & $\mathrm{~N}$ & $\mathrm{~N}$ & $\mathrm{~N}$ & $S$ & $\mathrm{~N}$ & $S$ & $\mathrm{~N}$ & $\mathrm{~N}$ & $\mathrm{~N}$ & $\mathrm{~N}$ & $\mathrm{~N}$ & $\mathrm{~N}$ & $\mathrm{~N}$ & $\mathrm{~N}$ & $\mathrm{~N}$ & $\mathrm{~N}$ \\
\hline 8 & Bibliografia básica & S & S & S & S & S & $\mathrm{N}$ & S & S & S & S & S & S & S & $\mathrm{N}$ & S & S & S \\
\hline 9 & Bibliografia complementar & $\mathrm{S}$ & $\mathrm{S}$ & $S$ & $\mathrm{~S}$ & S & $\mathrm{N}$ & S & $\mathrm{S}$ & $S$ & $S$ & $S$ & $S$ & $S$ & $\mathrm{~N}$ & S & $\mathrm{S}$ & S \\
\hline
\end{tabular}

O Quadro 4 revela que três IES do grupo 1 possuem todos os itens listados para o plano de ensino: 1 - Faculdade São Luis, 5 - PUCSP e 7 - Centro Universitário Ítalo-Brasileiro. A IES desse grupo com menos itens contemplados na estrutura dos planos de ensino foi a $6-$ Centro Universitário Fecap. Nenhuma IES do grupo 2 apresentou todos os itens esperados. A IES deste grupo com menos itens contemplados na estrutura foi a 7 - Unifai, e a com mais foi a 8 - Unicsul. Esse resultado sugere maior atenção dos docentes e coordenadores de cursos para melhorar a forma e o conteúdo dos planos de ensino.

Para a análise dos conteúdos oferecidos, foram criados cinco grupos semânticos: pessoa do perito; função pericial; relatórios periciais; honorários; importância e utilidade da prova técnica, na forma descrita na metodologia da pesquisa. A ordem de precedência dos grupos semânticos foi determinada pela frequência do conteúdo mais indicado em cada grupo. As Tabelas 1 e 2 apresentam os resultados desta parte da análise. 
TABELA 1

CONTEÚDOS APLICADOS NA DISCIPLINA DE PERÍCIA CONTÁBIL - GRUPO 1

\begin{tabular}{|c|c|c|c|c|}
\hline GRUPOS SEMÂNTICOS & GRUPOS SEMÂNTICOS & FREQUÊNCIA & CODIFICAĈ̣̃O & IMPORTÂNCIA \\
\hline $\begin{array}{l}\text { Importância e utilidade } \\
\text { da prova técnica }\end{array}$ & Prova pericial: judicial, arbitral e extrajudicial & 9 & 11 & 1 \\
\hline \multirow[t]{4}{*}{ Função pericial } & Aspectos técnicos, doutrinários, processuais e operacionais & 6 & 4 & \multirow[t]{4}{*}{2} \\
\hline & Procedimentos periciais & 3 & 5 & \\
\hline & Introdução a Perícia:conceituação, objetivos e história & 8 & 6 & \\
\hline & Estratégias de trabalho & 4 & 7 & \\
\hline \multirow[t]{2}{*}{ Relatórios periciais } & Relatórios periciais: laudo e parecer & 7 & 8 & \multirow[t]{2}{*}{3} \\
\hline & Papéis de trabalho & 1 & 9 & \\
\hline \multirow[t]{3}{*}{ Pessoa do perito } & Aspectos profissionais do perito & 5 & 1 & \multirow[t]{3}{*}{4} \\
\hline & $\begin{array}{l}\text { Cidadania e perícia contábil: responsabilidades sociais, civis } \\
\text { e criminais }\end{array}$ & 3 & 2 & \\
\hline & Responsabilidades compartilhadas & 2 & 3 & \\
\hline Honorários & Remuneração do trabalho pericial & 1 & 10 & 5 \\
\hline
\end{tabular}

A Tabela 1 indica, por ordem de importância, opinião mais estratificada do grupo 1 sobre os grupos semânticos, indicando a sequência: importância e utilidade da prova técnica, função pericial, relatórios periciais, pessoa do perito, e honorários.

\section{TABELA 2}

CONTEÚDOS APLICADOS NA DISCIPLINA DE PERÍCIA CONTÁBIL - GRUPO 2

\begin{tabular}{|c|c|c|c|c|}
\hline GRUPOS SEMÂNTICOS & GRUPOS SEMÂNTICOS & FREQUÊNCIA & CODIFICAC̣ÃO & IMPORTÂNCIA \\
\hline \multirow[t]{3}{*}{ Pessoa do perito } & Perfil profissional & 3 & 1 & \multirow[t]{3}{*}{1} \\
\hline & Cidadania e perícia: responsabilidades sociais, civis e criminais & 3 & 2 & \\
\hline & Perito e 0 assistente técnico & 1 & 3 & \\
\hline \multirow[t]{3}{*}{ Função pericial } & Normas sobre perícia & 3 & 4 & \multirow[t]{3}{*}{2} \\
\hline & Objetivos e espécie de perícia contábil & 1 & 5 & \\
\hline & Técnicas de trabalho pericial contábil & 2 & 6 & \\
\hline \multirow[t]{2}{*}{ Relatórios periciais } & Laudo e parecer pericial & 1 & 7 & \multirow[t]{5}{*}{3} \\
\hline & Os reletórios periciais & 1 & 8 & \\
\hline Honorários & Estimativa de honorários & 1 & 9 & \\
\hline \multirow{2}{*}{$\begin{array}{l}\text { Importância e utilidade } \\
\text { da prova técnica }\end{array}$} & Perícia contábil como prova & 1 & 10 & \\
\hline & Meios de prova & 1 & 11 & \\
\hline
\end{tabular}

A Tabela 2 revelou opinião menos estratificada para o grupo 2, com a seguinte ordem: a pessoa do perito, função pericial (semelhante ao grupo 1) e, no mesmo nível de importância, os relatórios periciais, honorários e importância e utilidade da prova técnica. Esses resultados são mais homogêneos do que os obtidos por Matos (2004) e Pereira (2006). Esses autores identificaram e/ou sugeriram vários temas, revelando grande dispersão para o estudo da disciplina, diferente do quanto aqui constatado. 
$\mathrm{Na}$ análise da bibliografia foram usadas as Tabelas 3 e 4, elaboradas a partir das proposições de Hofer, Peleias e Weffort (2005) e Peleias et al. (2008). Foram identificados, tabulados e analisados os itens dos cabeçalhos das tabelas.

\section{TABELA 3}

BIBLIOGRAFIA ADOTADA EM PERÍCIA CONTÁBIL DO GRUPO 1 - POR FREQUÊNCIA

\begin{tabular}{|c|c|c|c|c|c|c|}
\hline AUTOR & OBRA & ED. & ANO & EDITORA & $\mathbf{F}$ & $\mathbf{B} \mid \mathbf{C}\left({ }^{*}\right)$ \\
\hline \multirow[t]{3}{*}{ ALBERTO, V. L. P. } & \multirow[t]{3}{*}{ Perícia contábil } & $1^{a}$ & 1996 & \multirow[t]{3}{*}{ Atlas } & 3 & B \\
\hline & & $3^{\mathrm{a}}$ & 2002 & & 1 & C \\
\hline & & $2^{\mathrm{a}}$ & 2000 & & 1 & C \\
\hline \multirow[t]{5}{*}{ BRASIL } & Código de Processo Civil & $11^{\mathrm{a}}$ & 2005 & Saraiva & 2 & C \\
\hline & Novo Código Civil & & & & 1 & C \\
\hline & Código de Processo Civil & $31^{\mathrm{a}}$ & 2000 & Saraiva & 1 & $B$ \\
\hline & Resolução CFC 857/99 - NBCP2 & & 2005 & \multirow{3}{*}{$\begin{array}{l}\text { Conselho Federal de } \\
\text { Contabilidade }\end{array}$} & 3 & C \\
\hline & Resolução CFC 858/99 - NBCT13 & & 2005 & & 2 & C \\
\hline $\begin{array}{l}\text { CONSELHO FEDERAL DE } \\
\text { CONTABILIDADE }\end{array}$ & $\begin{array}{c}\text { Princípios Fundamentais e Normas Brasileiras } \\
\text { de Contabilidade Auditoria e Perícia }\end{array}$ & & 2005 & & 2 & B \\
\hline FIPECAFI/Arthur Andersen & Normas e Práticas Contábeis no Brasil & $2^{a}$ & 1994 & Atlas & 1 & C \\
\hline FRANCO, H. ,MARRA, E. & Auditoria Contábil & $2^{a}$ & 1997 & Atlas & 1 & C \\
\hline $\begin{array}{l}\text { IUDÍCIBUS, S., MARTINS, } \\
\text { E., GELBCKE, E. R. }\end{array}$ & $\begin{array}{l}\text { Manual de Contabilidade das Sociedades } \\
\text { por Ações }\end{array}$ & $5^{a}$ & 2000 & Atlas & 1 & C \\
\hline JESUS, F. & Perícia e Investigação de Fraude & $2^{a}$ & 2000 & $\mathrm{AB}$ & 1 & C \\
\hline \multirow[t]{3}{*}{ MAGALHÃES, A. D. F. et al } & \multirow{3}{*}{$\begin{array}{l}\text { Perícia contábil: uma abordagem teórica, } \\
\text { ética, legal, processual e operacional }\end{array}$} & $4^{\mathrm{a}}$ & 2003 & \multirow[t]{3}{*}{ Atlas } & 3 & C \\
\hline & & $2^{a}$ & 1998 & & 2 & B \\
\hline & & $1^{a}$ & 1995 & & 1 & B \\
\hline MONTEIRO, S. & Perícia contábil e Fiscal & $1^{\mathrm{a}}$ & 1973 & Juriscrédi & 1 & B \\
\hline MORAIS, A. C. & Perícia Judicial e Extrajudicial & $1^{\mathrm{a}}$ & 2000 & Intertexto & 1 & C \\
\hline ORNELAS, M. M. G. & $\begin{array}{l}\text { Avaliações de sociedade: apuração de } \\
\text { haveres em processos judiciais }\end{array}$ & $2^{a}$ & 2003 & Atlas & 1 & C \\
\hline ORNELAS, M. M. G. & Perícia contábil & $4^{\mathrm{a}}$ & 2003 & Atlas & 7 & $\mathrm{~B} / \mathrm{C}$ \\
\hline QUEIROZ, J. & Código Civil e CPC & & & Saraiva & 1 & C \\
\hline \multirow[t]{4}{*}{ SÁ, A. L. } & \multirow[t]{2}{*}{ A Perícia contábil } & $3^{\mathrm{a}}$ & 1997 & \multirow[t]{4}{*}{ Atlas } & 1 & C \\
\hline & & $6^{\mathrm{a}}$ & 2003 & & 2 & C \\
\hline & \multirow[t]{2}{*}{ Perícia contábil } & $7^{\mathrm{a}}$ & 2005 & & 2 & B \\
\hline & & $5^{a}$ & 2002 & & 1 & B \\
\hline VAZ. A. & Perícias Contábeis Judiciais. Manual Prático & $1^{a}$ & 1996 & Thomson & 1 & B \\
\hline $\begin{array}{l}\text { ZARZUELA, J. L.; MATUNAGA, } \\
\text { M.; THOMAZ, P. L. }\end{array}$ & Laudo Pericial & $1^{\mathrm{a}}$ & 2000 & Revistas dos Tribunais & 1 & C \\
\hline
\end{tabular}

$\mathrm{B} / \mathrm{C}$ - indicam bibliografia básica ou complementar

Na bibliografia usada pelo grupo 1, destacou-se o autor Ornelas, com oito indicações da obra Perícia Contábil. Outros autores mais indicados foram Magalhães e Sá - seis vezes - e Alberto - cinco vezes. Não houve predominância dessas obras como básica (B) ou complementar (C).

Na bibliografia complementar, destacaram-se Magalhães e Sá, com três indicações cada. O Conselho Federal de Contabilidade teve três indicações para a NBCP2 e duas para a NBCT13. Diferentemente do quanto constatado por Hofer, Peleias e Weffort (2005) e por Peleias et al. 
(2008), em apenas uma obra (Novo Código Civil) houve ausência de elementos de identificação da obra.

Foram indicadas três obras contábeis (Normas e Práticas Contábeis, Auditoria Contábil e Manual de Contabilidade das Sociedades por Ações), a princípio aplicáveis a outras disciplinas. Sobre a distinção entre Perícia Contábil e Auditoria, no futuro poderá ser investigado se é apresentada aos discentes a diferença entre essas áreas de atuação para os Contadores, fato apontado pelos trabalhos internacionais analisados (STIMPSON, 2007; BROOKS; LABELLE, 2006; ROSEN, 2006; REZAEE; LANDER; GAVIN, 1992) e na obra de Sá (2004). Apesar da sutil diferença no título, a obra indicada de Sá é a mesma, mudando as edições.

\section{TABELA 4}

BIBLIOGRAFIA ADOTADA EM PERÍCIA CONTÁBIL DO GRUPO 2 - POR FREQUÊNCIA

\begin{tabular}{|c|c|c|c|c|c|c|}
\hline AUTOR & OBRA & ED. & ANO & EDITORA & $\mathbf{F}$ & $\mathbf{B} / \mathbf{C}\left(\mathbf{*}^{*}\right)$ \\
\hline \multirow[t]{2}{*}{ ALBERTO, V.L.P. } & Perícia contábil & $3^{a}$ & 2002 & \multirow[t]{2}{*}{ Atlas } & 3 & B \\
\hline & $\begin{array}{l}\text { Perícia contábil: normas brasileiras de } \\
\text { perícia contábil comentadas }\end{array}$ & $3^{\mathrm{a}}$ & 2005 & & 2 & C \\
\hline \multirow[t]{4}{*}{ BRASIL } & Código de Processo Civil & & 2005 & & 1 & C \\
\hline & Resolução CFC 857/99 - NBCP2 & & 2005 & \multirow{2}{*}{$\begin{array}{l}\text { Conselho Federal de } \\
\text { Contabilidade }\end{array}$} & 5 & C \\
\hline & Resolução CFC 858/99 - NBCT13 & & 2005 & & 4 & B \\
\hline & Código de Processo Civil & $31^{\mathrm{a}}$ & 2000 & Saraiva & 3 & C \\
\hline \multirow[t]{6}{*}{ MAGALHÃES, A.D.F. et al } & \multirow{6}{*}{$\begin{array}{l}\text { Perícia contábil: uma abordagem teórica, } \\
\text { ética, legal, processual e operacional }\end{array}$} & $7^{\mathrm{a}}$ & & \multirow[t]{6}{*}{ Atlas } & 2 & C \\
\hline & & & 2005 & & 2 & $\mathrm{~B}$ \\
\hline & & $3^{a}$ & 2001 & & & \\
\hline & & $5^{a}$ & & & 1 & C \\
\hline & & $5^{a}$ & & & 1 & C \\
\hline & & $2^{a}$ & 1998 & & 1 & C \\
\hline MAGALHÄES, A. J. F. et al & $\begin{array}{l}\text { Perícia contábil: uma abordagem teórica, } \\
\text { ética, legal, processual operacional }\end{array}$ & $4^{\mathrm{a}}$ & 2004 & Atlas & 1 & $\mathrm{~B}$ \\
\hline $\begin{array}{c}\text { NEGRÃO, T.; } \\
\text { GOUVEIA, J.R.F. }\end{array}$ & $\begin{array}{c}\text { Código de Processo Civil e Legislação } \\
\text { Processual em Vigor }\end{array}$ & $38^{a}$ & 2005 & Saraiva & 1 & C \\
\hline \multirow[t]{2}{*}{ ORNELAS, M.M.G. } & \multirow[t]{2}{*}{ Perícia contábil } & & 2007 & \multirow[t]{2}{*}{ Atlas } & 2 & C \\
\hline & & $4^{a}$ & 2003 & & 6 & B \\
\hline \multirow[t]{5}{*}{ SÁ, A.L. } & A Perícia contábil & $7^{a}$ & 2007 & Atlas & 1 & $\mathrm{~B}$ \\
\hline & \multirow[t]{4}{*}{ Perícia contábil } & $4^{\mathrm{a}}$ & 2000 & \multirow[b]{4}{*}{ Atlas } & 1 & B \\
\hline & & $7^{a}$ & 2005 & & 1 & B \\
\hline & & $3^{a}$ & 1997 & & 1 & B \\
\hline & & $5^{a}$ & 2002 & & 1 & B \\
\hline SILVA, M.A. & Fundamentos da Perícia Contábil: teoria e prática & $2^{a}$ & 2006 & UMESP & 2 & $\mathrm{~B}$ \\
\hline ZANNA, R.D. & Prática de Perícia Contábil & $2^{\mathrm{a}}$ & 2006 & Atlas & 2 & C \\
\hline
\end{tabular}

$\mathrm{Na}$ bibliografia usada pelo grupo 2, destacou-se o autor Magalhães, com sete indicações, seguido de Ornelas e Sá, com seis, e Alberto, com cinco menções. As Resoluções do CFC foram indicadas em cinco programas. Assim como no grupo 1, algumas obras são usadas de forma intercalada como básica (B) e complementar (C). 
Observou-se o mesmo erro de menção ao título da obra de Sá e a menção errada a parte do nome do autor Magalhães, pois o correto é "de Deus", e, em um plano de ensino, constatou-se a expressão "de Jesus". Diferentemente do grupo 1, neste constatou-se a ausência de menção à editora da uma edição da obra de Alberto e a não indicação do ano para duas edições da obra de Magalhães. Não foram indicadas obras aplicáveis a outras disciplinas.

Houve ocorrências comuns aos dois grupos. Foram indicadas normas emanadas do CFC. Predominou a editora Atlas nas obras sobre Perícia, semelhantemente ao apontado por Hofer, Peleias e Weffort (2005). Nas obras sobre legislação, predominou a editora Saraiva.

Não se constatou, na bibliografia dos dois grupos, a indicação de artigos publicados em revistas, de dissertações, teses e de trabalhos apresentados em eventos da área contábil. O estudo dessas publicações ajudaria a criar o círculo virtuoso apontado por Ott (2008), pois além de relatarem resultados de pesquisas recentes, estimulariam o interesse pela iniciação científica, pela participação em eventos e pela elaboração e publicação de artigos. Essa constatação merece ser investigada, pois todos os docentes que colaboraram com a pesquisa eram pelo menos mestrandos, que conhecem e convivem ou conviveram com os programas de pós-graduação stricto sensu. Infere-se que, ao saberem da importância e da utilidade dos referidos trabalhos, os docentes deveriam incentivar sua utilização pelos alunos.

É preciso destacar o fato de todos os docentes serem ao menos mestrandos e dois dos três professores da PUC-SP serem doutores em Ciências Contábeis, uma evolução em relação ao trabalho de Buosi (1999). Uma explicação é que a cidade de São Paulo abriga quatro programas de pós-graduação stricto sensu em Ciências Contábeis, um dos quais o único a oferecer, à época da pesquisa, o doutorado em Ciências Contábeis.

Em todas as IES pesquisadas constatou-se o regime semestral para um curso de quatro anos. A denominação mais frequente foi "Perícia Contábil". A expressão "Arbitragem" constou da disciplina de uma IES do grupo 1 e de uma do grupo 2. A expressão "Normas Profissionais" teve uma ocorrência. Apenas a PUC-SP mencionou conteúdos de arbitragem.

Duas IES do grupo 1 revelaram carga horária de 80 horas semestrais. A Unip apresentou 80 horas para a disciplina, 40 horas a cada semestre, nas disciplinas "Perícia Contábil" e "Normas Profissionais de 
Perícia Contábil”. Uma IES ofereceu 72 horas e três, 60 horas. A Tabela 5 contém os dados constatados para o grupo 1 .

TABELA 5

CARGA HORÁRIA PARA A DISCIPLINA DE PERÍCIA CONTÁBIL GRUPO 1

\begin{tabular}{|c|c|c|c|}
\hline DISCIPLINAS & & & $N^{0}$ de disciplinas \\
\hline SEMESTRE & $\mathbf{I}$ & II & \\
\hline 1 - Perícia Contábil & 80 & - & 2 \\
\hline 2 - Normas Profissionais de Perícia Contábil & $\cdot$ & 40 & 1 \\
\hline $3-$ Perícia Contábil & 40 & $\cdot$ & 1 \\
\hline 4 - Perícia Contábil & 60 & - & 2 \\
\hline 5 - Perícia Contábil & 72 & - & 1 \\
\hline 6 - Perícia Contábil e Arbitragem & 60 & - & 1 \\
\hline Total & & & 8 \\
\hline
\end{tabular}

Duas IES do grupo 2 apresentaram carga horária de 80 horas semestrais. Assim como a Unip no grupo 1, a Faculdade Famater apresentou 80 horas, distribuídas em 40 horas a cada semestre, nas disciplinas "Perícia Contábil I" e "Perícia Contábil II". Uma IES relatou 68 horas, uma, 60 horas, e em 5 foram constatadas 40 horas semestrais. A Tabela 6 contém os dados apurados para o grupo 2 .

\section{TABELA 6}

CARGA HORÁRIA PARA A DISCIPLINA DE PERÍCIA CONTÁBIL GRUPO 2

\begin{tabular}{|c|c|c|c|}
\hline DISCIPLINAS & & & $N^{0}$ de disciplinas \\
\hline SEMESTRE & I & II & \\
\hline 1 - Perícia Contábil & 80 & $\cdot$ & 2 \\
\hline 2 - Perícia e Arbitragem & 60 & - & 1 \\
\hline 3 - Perícia Contábil & 68 & - & 1 \\
\hline 4 - Perícia Contábil II & $\cdot$ & 40 & 1 \\
\hline 5 - Perícia Contábil I & 40 & $\cdot$ & 1 \\
\hline 6 - Perícia Contábil & 40 & - & 5 \\
\hline Total & & & 8 \\
\hline
\end{tabular}

A análise da quantidade de horas aula semestrais oferecidas revelou carga horária maior ou igual a 60 horas em 6 de 8 ocorrências no grupo 1, e em 5 de 11, para o grupo 2. Os dados demonstram que as IES do grupo 1 designam maior número de horas-aula por semestre para a disciplina.

A Tabela 7 resume as estratégias de ensino usadas pelos dois grupos de IES. 
TABELA 7

ESTRATÉGIAS DE ENSINO USADAS PELOS GRUPOS DE IES

ESTRATÉGIA DE ENSINO

FREQUÊNCIA

\begin{tabular}{|c|c|c|}
\hline & \\
\hline & Grupo 1 & Grupo 2 \\
\hline Aulas em laboratório & 1 & 1 \\
\hline Aulas expositivas & 6 & 5 \\
\hline Discussão por parte dos alunos; preleção dos temas pelos alunos & 2 & 1 \\
\hline $\begin{array}{l}\text { Estudo de casos; trabalhos extras; exercícios de fixação individuais e em grupo; } \\
\text { Exercícios em classe; resolução de casos práticos sobre perícia contábil }\end{array}$ & 8 & 3 \\
\hline Palestra com perito contador & 2 & 1 \\
\hline Pesquisas extraclasse & 1 & \\
\hline Trabalhos extras & 2 & \\
\hline Visita e entrevista com peritos contadores & 2 & \\
\hline Leitura de artigos & 1 & 1 \\
\hline Totais & 22 & 12 \\
\hline
\end{tabular}

O primeiro destaque foi a menção à expressão "estudo de casos", presente em oito IES do grupo 1 e três do grupo 2. Assim como identificado nos trabalhos de Pereira (2006) e de Neves Jr. e Brito (2007), os docentes confundem a estratégia de pesquisa do "estudo do caso" com a técnica de ensino do "método do caso", fato apontado por César (2005). Esse ponto merece a atenção dos docentes e coordenadores. O segundo destaque foi a maior variedade de estratégias de ensino no grupo 1, com 22 ocorrências contra 12 do grupo 2. É um indicativo de que os docentes do grupo 1 usaram mais estratégias na oferta da disciplina, em comparação com o trabalho de Pereira (2006).

Esperava-se que a aula expositiva apresentasse maior frequência de uso, fato constatado nos dois grupos. Um fato a destacar foi a quantidade de menções a trabalhos extras, isoladamente ou em grupo, com outras estratégias. Merecem comentário o estímulo à discussão por parte dos alunos, as visitas e entrevistas com peritos contadores e a leitura de artigos. As entrevistas e os artigos são meios de integrar a realidade profissional com a sala de aula, bem como de tornar público o resultado de pesquisas sobre o tema, apesar da constatação da não indicação de artigos na bibliografia.

Os critérios de avaliação usados pelos dois grupos estão listados na Tabela 8. 


\section{TABELA 8}

CRITÉRIOS DE AVALIAC̣ÃO USADOS PELOS GRUPOS DE IES

\begin{tabular}{c|c|c} 
CRITÉRIOS DE AVALIAC̣ÃO & \multicolumn{2}{|c}{ FREOUÊNCIA } \\
\hline Participações em questionamentos e debates & Grupo 1 & Grupo 2 \\
\hline Provas & 2 & 2 \\
\hline Trabalhos em grupo & 8 & 10 \\
\hline Seminários & 1 & 1 \\
\hline Trabalhos e exercícios desenvolvidos em classe e extraclasse & & 5
\end{tabular}

Da mesma forma que para a aula expositiva, era esperada a predominância das provas, o que de fato se constatou. Na sequência predominaram os trabalhos e exercícios desenvolvidos em classe e extraclasse, e as participações em questionamentos e debates. Os trabalhos em grupo e os seminários tiveram uma ocorrência cada.

\section{CONSIDERAC̦ÕES FINAIS}

Nos dois grupos de IES objeto da pesquisa, a disciplina Perícia Contábil é ministrada no último ano, na maioria dos casos, no último semestre letivo. Dos conteúdos ministrados no grupo 1, destacam-se a importância e a utilidade da prova técnica, seguida pela função pericial contábil. O grupo 2 destaca a pessoa do perito e função pericial contábil. Os dois grupos apresentaram, nos planos de ensino, os cinco grandes tópicos obtidos na análise das obras mais indicadas: pessoa do perito, função pericial, relatórios periciais, honorários e importância e utilidade da prova técnica.

Constatou-se que seis das sete IES do grupo 1 destinam entre 60 e 80 horas para a disciplina e, no grupo 2, cinco entre dez ficam na mesma condição de carga horária. A bibliografia básica e complementar é similar nos dois grupos. Destacou-se o autor Ornelas, com 16 indicações, seguido pelas resoluções do Conselho Federal de Contabilidade, com 14 indicações. Nenhum plano de ensino revelou a indicação de artigos científicos na bibliografia.

Quanto às estratégias de ensino usadas no grupo 1, destaca-se o método do caso, presente nas sete IES. Em seguida, aparece a aula expositiva, presente em seis IES. O grupo 2 evidencia as aulas expositivas em cinco IES. Logo após, aparece a estratégia de método de caso, presente 
em três IES. Nos dois grupos constatou-se a confusão dos docentes entre a estratégia de ensino do método do caso com a técnica de pesquisa do estudo de caso.

Os critérios de avaliações apresentados por ambos os grupos destacam a aplicação de provas, presente em dezessete IES nos dois grupos.

A qualificação dos professores que lecionam a disciplina está entre mestrando, mestre e dois doutores, estes na PUC-SP.

A análise revelou que o grupo das IES classificadas pelo Enade elabora e entrega aos alunos planos de ensino mais completos em relação aos itens de análise inseridos no Quadro 1, o que não acontece com o outro grupo dos dez cursos escolhidos por acessibilidade.

Alguns achados requerem maior atenção dos coordenadores e docentes da disciplina. Inicia-se pela incompletude de alguns planos de ensino. Três cursos do grupo 1 possuem todos os itens considerados necessários; entretanto, nenhum dos cursos do grupo 2 possui todos os itens. Na bibliografia, constatou-se a não indicação de artigos publicados em revistas, tampouco de pesquisas recentes sobre Perícia Contábil, existentes em teses e dissertações que vêm sendo apresentadas nos Programas de Pós-Graduação em Ciências Contábeis. Quanto à ausência de artigos e pesquisas na bibliografia indicada, causa mais estranheza o fato de que, à época da pesquisa, todos os docentes pesquisados eram pelo menos mestrandos.

Foram constatados erros e incompletudes na bibliografia indicada pelas IES do grupo 2, já apontados em pesquisas anteriores. Esse problema requer acompanhamento e supervisão dos planos de ensino pelos coordenadores de curso. Outro fator que chama a atenção negativamente é a menção ao termo "estudo de caso" como estratégia de ensino em oito planos de ensino no grupo 1 e em três, do grupo 2. Nesse caso, sugere-se que os coordenadores de curso e professores responsáveis por aqueles planos de ensino participem de programas de reciclagem em Metodologia de Pesquisa e Didática do Ensino Superior que abordem as diferenças entre a técnica de pesquisa do estudo de caso e a estratégia de pesquisa do método do caso.

Espera-se que a publicação deste artigo ofereça subsídios para que os coordenadores de curso e os professores da disciplina Perícia Contábil possam solucionar os problemas apontados, o que melhorará as condições de ensino da disciplina. 
Pesquisas futuras poderão estudar formas de promover a integração entre o que é tratado em sala de aula com a realidade objetiva da Perícia Contábil. Poderá ser investigada a forma de realização de atividades, tais como: entrevistas com peritos e análises dos laudos por eles produzidos; palestras com peritos atuantes; palestras com juízes acostumados a nomear peritos; e o desenvolvimento e aplicação de casos no ensino de Perícia Contábil, de acordo com os requisitos necessários à aplicação eficaz do método do caso no ensino da disciplina.

Para finalizar, sugere-se replicar a pesquisa para analisar as condições de ensino de Perícia Contábil em outras regiões brasileiras. 


\section{REFERÊNCIAS}

ABREU, M. C.; MASETTO, M. T. O professor universitário em aula. 8 ed. São Paulo: Ed. Associados, 1990.

BARDIN, L. Análise de conteúdo. Tradução Luís Antero Reto e Augusto Pinheiro. 3 ed. Lisboa: Edições 70, 2004.

BRASIL, Decreto 1.339, de 09 de jan 1905. Declara instituições de utilidade publica a Academia de Commercio do Rio de Janeiro, reconhece os diplomas por ella conferidos, como de caracter official; e dá outras providencias. Senado Federal. Disponível em: $<$ http://www.senado.gov.br/servlets/NJUR.Filtro?tipo $=$ DEC\&secao=NJUILEGBRAS\&n $>$. Acesso em: 5 Set. 2007.

BRASIL. Decreto 20.158, de 30 de jun de 1931. Organiza o ensino comercial, regulamenta a profissão de contador e dá outras providências. Senado Federal. Disponível em: $<$ http://wwwt.senado.gov.br/servlets/NJUR.Filtro?tipo $=$ DEC\&secao $=$ N.../npn-brs.exe\&seq $=00>$. Acesso em: 09 Set. 2004.

BRASIL. Decreto 17.329, de 28 de mai de 1926. Aprova, o regulamento para os estabelecimentos de ensino technico commercial reconhecidos officialmente pelo Governo Federal. Senado Federal. Disponível em:

$<$ http://wwwt.senado.gov.br/servtets/NJUR.Filtro?tipo $=$ DEC\&secao $=N /$ nph-brs.exe\&seq $=00>$. Acesso em: 09 Jul. 2007.

BRASIL. Lei 1.401, de 31 de Jul de 1951. Inclui, no curso de ciências econômicas, a cadeira de História Econômica Geral e do Brasil, e desdobra o curso de ciências contábeis e atuariais. Senado Federal. Disponível em:

$<$ http://wwwt.senado.gov.br/serviets/NJUR.filtro?tipo $=$ LEI\&secao $=N J j . . . /$ npn-brs.exe\&seq $=00>$. Acesso em: 05 Set. 2007.

BRASIL. Lei 7.988, de 22 set de 1945. Dispõe sobre o ensino superior de ciências econômicas e de ciências contábeis e atuariais. Senado Federal. Disponível em:

$<$ wwwt.senado.gov.br/servlets/NJUR.Filtro?tipo=DEL\&secao=NJUILEGBRAS\&n...> . Acesso em: 05 Set. 2007.

BRASIL. Lei 1.535, de 23 de ago de 1939. Altera a denominação do Curso de Perito Contador e dá outras providências. Senado Federal. Disponível em:

$<$ http://wwwt.senado.gov.br/serviets/NJUR.Filtro?tipo=DEL\&secao $=$ NJ.../npn-brs.exe\&seq $=00>$. Acesso em: 05 Set. 2007.

BRASIL. Ministério da Educação. Parecer CFE n. 397/62. Divide os cursos de Ciências Econômicas, Ciências Contábeis e Ciências Atuariais nos ciclos básicos e de formação profissional. Documenta Rio de Janeiro: Guanabara, n. 11, janeiro-fevereiro/1963.

BRASIL. Ministério da Educação. Resolução CFE s/ n., de 08/02/1963. Fixa os mínimos de conteúdo e duração dos cursos de Ciências Atuariais, Ciências Contábeis e Ciências Econômicas. Passarinho, Yesis Ilícia (org). Resoluções e Portarias do Conselho Federal de Educação -1962/1978. Brasília: DF - CFE - 1979.

BRASIL. Ministério da Educação. Conselho Nacional de Educação. Resolução CNE/CES 06/2004. Brasília: 2004. Disponível em:

<http://portal.mec.gov.br/cne/arquivos/pdf/rces06_04.pdf>. Acesso em: 25 Set. 2007.

BRASIL. Ministério da Educação. Conselho Nacional de Educação. Resolução CNE/CES 
10/2004. Brasília: 2004. Disponível em:

<http://portal.mec.gov.br/cne/arquivos/pdf/rces10_04.pdf>. Acesso em: 25 Set. 2007.

BRASIL. Ministério da Educação. Conselho Nacional de Educação. Parecer CNE/CES 67/2003. Brasília: 2004. Disponível em:

<http://www.mec.gov.cne/diretrizes.shtm\#cienciascontabeis>. Acesso em: 08 Ago. 2007.

BRASIL. Ministério da Educação. Conselho Nacional de Educação. Parecer CNE/CES 146/2002. Brasília: 2002. Disponível em:

<http://www.mec.gov.cne/diretrizes.shtm\#cienciascontabeis>. Acesso em: 08 Ago. 2007.

BRASIL. Ministério da Educação. Conselho Nacional de Educação. Parecer CNE/CES 0289/2003. Brasília: 2003. Disponível em:

<http://www.mec.gov.cne/diretrizes.shtm\#cienciascontabeis>. Acesso em: 08 Ago. 2007.

BRASIL. Ministério da Educação. Conselho Nacional de Educação. Resolução CFE 03, de 14 de out de 1992. Fixa os mínimos de conteúdo e duração do curso de graduação em Ciências Contábeis. Conselho Federal de Educação.

BRASILa. Conselho Federal de Contabilidade. Resolução n. 1243, de 10 de dezembro de 2009. Aprova a NBC TP 01 - Perícia Contábil. Disponível em:

<http://www.cfc.org.br/sisweb/sre/detalhes_sre.aspx?Codigo $=2009 / 001243>$. Acesso em: 09 Set. 2011.

BRASILb. Conselho Federal de Contabilidade. Resolução n. 1244, de 10 de dezembro de 2009, Aprova a NBC PP 01 - Perito Contábil. Disponível em:

http://www.cfc.org.br/sisweb/sre/detalhes_sre.aspx?Codigo=2009/001244>. Acesso em: 09 Set 2011.

BROOKS, L. J.; LABELLE, L. J. CAP Forum on forensic accounting in the post-Enron world: education for investigative and forensic accounting. Canadian Accounting Perspectives, Toronto, v. 5, n. 2, p. 287-306, 2006.

BUOSI, V. Uma contribuição para o ensino de perícia contábil. 1999, 163 p. Dissertação. (Mestrado em Ciências Contábeis e Financeiras) - Universidade Católica de São Paulo, São Paulo, 1999.

- Resolução 857/1999 Normas Profissionais do Perito. São Paulo. Disponível em: <http://www.cfc.org.br/sisweb/sre/detalhes_sre.aspx?Codigo $=1999 / 000857>$. Acesso em: 25 Jun. 2008.

- Resolução 858/1999 Perícia Contábil. São Paulo. Disponível em: <http://www.cfc.org.br/sisweb/sre/detalhes_sre.aspx?Codigo $=1999 / 000858>$. Acesso em: 25 Jun. 2008.

CÉSAR, A. M. R. V. C. Método do estudo de caso (Case Studies) ou método do caso (Teaching cases)? Uma análise dos dois métodos no ensino e pesquisa em Administração. Revista Eletrônica Mackenzie de Casos. São Paulo, v. 1, n. 1, 2005. Disponível em: <http://www.mackenzie.br/fileadmin/Graduacao/CCSA/remac/jul_dez_05/06.pdf>. Acesso em: 30. Set. 2009.

COOPER, D. R.; SCHINDLER, P. S. Métodos de pesquisa em administração. Tradução Luciana de Oliveira Rocha. 7 ed. Porto Alegre: Bookman, 2003. 
HOFER, H.; PELEIAS, I. R.; WEFFORT, E. F. J. Análise das Condições de Oferta da Disciplina de Contabilidade Introdutória: Pesquisa junto às Universidades Estaduais do Paraná. Revista de Contabilidade e Finanças, São Paulo, n. 39, p. 118-135, 2005. Disponível em: $<$ http://www.eac.fea.usp.br/cadernos/completos/cad39/dtrabalho_elza_ivam_elionor_pg118a135.pdf>. Acesso em: 25 Set. 2007.

LUNA, S. V. Planejamento de pesquisa: uma introdução. São Paulo: Educ, 2002.

MALHOTRA, N. K. Pesquisa de marketing: uma orientação aplicada. 4 ed. Porto Alegre: Bookman, 2006.

MARCIS, J. G.; KELLER JR., C. E.; DECK, A. B.; CARR, D. R. A survey of faculty views regarding the course syllabus. Journal of Accounting and Finance Research, [S.l.], v. 13, n. 4, p. 185-191, Oct. 2005.

MARION, J. C. O ensino da contabilidade. 2 ed. São Paulo: Atlas, 2001.

MATOS, A. S. A visão dos professores dos cursos de Ciências Contábeis de Salvador sobre o conteúdo da disciplina perícia contábil. 169 p. Dissertação (Mestrado em Contabilidade) - Fundação Visconde de Cairu, Salvador, 2004.

NEVES JR., I. J.; BRITO, C. P. Proposições ao ensino da perícia contábil no Distrito Federal. In: CONGRESSO DE INICIAÇÃO CIENTIFICA - USP, 4., 2007. São Paulo, p. 01-15. 2007. Disponível em: <http://www.congressoeac.locaweb.com.br/artigos72007/53.pdf>. Acesso em: 27 Ago. 2008.

OTT, E. Reflexão sobre a Pesquisa em Contabilidade no Brasil. In: LOPES, J.; RIBEIRO FILHO, J. F.; PEDERNEIRAS, M. (Org.) Educação contábil: tópicos de ensino e pesquisa. São Paulo: Atlas, 2008.

PELEIAS, I. R.; SINATORA, J. R. P; FARIA, A. C.; SILVA, D. Análise das condições de oferta da disciplina sistemas de informação: pesquisa com cursos de Ciências Contábeis na cidade de São Paulo. In: LOPES, J.; RIBEIRO FILHO, J. F.; PEDERNEIRAS, M. (Org.) Educação contábil: tópicos de ensino e pesquisa. São Paulo: Atlas, 2008.

PEREIRA, A. C. Perícia contábil: conteúdo programático e propostas metodológicas. 2006. 221 p. Dissertação (Mestrado em Ciências Contábeis e Atuariais) - Universidade Católica de São Paulo, São Paulo, 2006.

PETERSON, B. K. Fraud education for accounting students. Journal of education for business, Montana, v. 78, n. 5, p. 263-267, May-June 2003.

PONEMON, L.A. Arguments against the CPA Exam to gauge Accounting program sucess. New York, v. 13, n. 2, p. 421-424, May 1998.

QUEIRÓZ, D. A; PALMA, M. R. B. A gestão do currículo do curso superior de Ciências Contábeis. In: PELEIAS, I. R. Didática do ensino da contabilidade: aplicável a outros cursos superiores. São Paulo: Saraiva, 2006. p. 179-224.

REZAEE, Z.; LANDER, G. H.; GAVIN, T. A. Integrating forensic accounting into the accounting curriculum, Tennessee, p. 25-29, 1992.

ROSEN, L. S. Forensic accounting: where and when headed? Canadian Accounting Perspectives, Toronto, v. 5, n. 2, p. 257-264, 2006.

SÁ, A. L. Perícia contábil. 6 ed. São Paulo: Atlas, 2004.

STIMPSON, J. Forensic accounting: exponential growth. Practical Accountant, New York. 40, n. 2, p. 18-24, Feb. 2007.

VERGARA. S. C. Projetos e relatórios de pesquisa em administração. 4 ed., São Paulo: Atlas, 2003. 


\section{NOTAS}

1 Os autores são responsáveis pelo conteúdo e pelas ideias expressas no trabalho.

2 Optou-se, aqui e em outros pontos do texto, por manter a redação original.

Recebido: $13 / 04 / 2010$

Aprovado: 18/08/2011

Contato:

Ivam Ricardo Peleias

Centro Universitário FECAP

Programa de Mestrado em Ciências Contábeis

Avenida Liberdade, 532

CEP 01502-001

São Paulo, SP

Brasil 